\title{
Generation of stable, non-aggregating Saccharomyces cerevisiae wild isolates*
}

\author{
Dominika M. Wloch-Salamon $\bowtie$, Marcin Plech and Jagoda Majewska \\ Institute of Environmental Sciences, Jagiellonian University, Kraków, Poland
}

\begin{abstract}
Cellular aggregates observed during growth of Saccharomyces cerevisiae strains derived from various natural environments makes most laboratory techniques optimized for non-aggregating laboratory strains inappropriate. We describe a method to reduce the size and percentage of the aggregates. This is achieved by replacing the native allele of the $A M N 1$ gene with an allele found in the W303 laboratory strain. The reduction in aggregates is consistent across various environments and generations, with no change in maximum population density or strain viability, and only minor changes in maximum growth rate and colony morphology.
\end{abstract}

Key words: AMN1, aggregation, Saccharomyces cerevisiae

Received: 25 September, 2013; revised: 22 November, 2013; accepted: 25 November, 2013; available on-line: 20 December, 2013

\section{INTRODUCTION}

With its long history in laboratory research, budding yeast has been one of the most intensively used model organisms, and there it is hope that it will be the pre-eminent model organism of the 21 st century (Botstein \& Fink, 2011). Since 1996, when the genome sequence of Saccharomyces cerevisiae was published (Goffeau et al., 1996; Mewes et al., 1997), the amount of accumulated data on its molecular genetics and evolution has increased tremendously. However, knowledge about this species' natural environment, life history, population genetics, and ecology is still incomplete. Because such research cannot be done using the few available laboratory yeast strains, there is interest in strains isolated from various geographical and ecological environments (Diezmann \& Dietrich, 2009; Liti et al., 2009; Schacherer et al., 2009) and in the pathogenic effects of clinical $S$. cerevisiae strains.

Two reasons why yeast laboratory strains are so widely used are that they are heterothallic and that they are able to form a homogeneous, non-aggregating and nonadhesive planktonic population in liquid laboratory media (Bruckner \& Mosch, 2012; Mortimer \& Johnston, 1986). This has allowed for optimization of many basic and indispensible techniques used in the yeast laboratories, such as: assessment of cell number based on optical density measurements; determination of colony forming units (CFU) on agar media (e.g., for viability measurements); "streaking" to obtain colonies derived from single cells; fluorescence-activated cell sorting (FACS); Coulter Counter measurements; efficient staining due to equal availability of the dye for all of the cells; fractionation in various density gradients; and many others. Unfortunately, many wild isolates form large robust aggregates of cells during growth in liquid media ("clumpy" phenotype), rendering these techniques inaccurate, very laborious, or even impossible to perform with such strains.

It was shown that the clumpy phenotype of the wild isolate RM11 depends on variation in $A M N 1$, a gene involved in daughter cell separation (Yvert et al., 2003). Nucleotide sequencing of AMN1 cDNAs from laboratory strains (BY series and related: W303 and S288C) identified the missense mutation: an $\mathrm{A}$ to $\mathrm{T}$ change at nucleotide position 1104, which results in an amino acid substitution of Val368 for aspartic acid (D368V). In contrast, most wild isolates (RM11) have aspartic acid (D) at the corresponding position of wtAMN1 protein (www. yeastgenome.org). Deletion of the amn 1 gene gives the aggregating RM11 strain a non-aggregating phenotype (Yvert et al., 2003). This deletion has been shown to result in decreased vegetative growth rate, competitive fitness, in filamentous growth, and a deficiency in invasive growth (www.yeastgenome.org). When the $A M N 1$ allele from laboratory yeast (W303), was replaced by AMN1RM11, (an allele from the wild yeast strain RM11), the lab strains acquired the clumpy phenotype of wild yeast (Koschwanez et al., 2011).

We report a new genetic technique for obtaining a non-aggregating population from a previously aggregating $S$. cerevisiae strain.

\section{MATERIALS AND METHODS}

We used seven starting strains (listed in Table 1); all are haploid and come from an existing collection of wild isolates in which $H O$ and $U R A 3$ genes were replaced by antibiotic markers, HygMX4 and KanMX4 cassettes, respectively (Cubillos et al., 2009). Plasmid pJHK110, containing the laboratory allele of $A M N 1-$ W303 (kindly provided by John Koschwanez, FAS Center for Systems Biology, Harvard University), was cut with Xho1 enzyme to target integration at the $A M N 1$ locus, and then transformed into the strains (Gietz \& Woods, 2002), selecting for URA prototrophy via growth on synthetic complete media without uracil (SC-ura) plates. After 2 to 3 days of incubation, at least eight of the obtained transformants were streaked out onto new SC-ura plates. Individual colonies from these plates were then transferred into liq-

e-mail: dominika.wloch-salamon@uj.edu.pl

*Presented at the 3-rd Workshop on Microbiology "MIKROBIOT $2013^{\prime \prime}$ in Łódź, Poland.

Abbreviations: $A M N 1$ gene, antagonist of mitotic exit network gene; FACS, fluorescence-activated cell sorting; cDNA, complementary DNA; HygMX4, hygromycin antibiotic marker; KanMX4 geneticin antibiotic marker; SC-ura, synthetic complete medium without uracil; YPD, yeast peptone dextrose medium; 5-FOA, 5-Fluoro-ortic acid medium; OD, optical density; MGR, maximum growth rate 
Table. 1. a) Strains positively transformed with pJHK_110_amn1_W303 inducing the AMN1 gene to switch into the laboratory W303 allele.

\begin{tabular}{|c|c|c|c|c|c|c|c|}
\hline \multirow[b]{2}{*}{ Parental strains } & \multirow[t]{2}{*}{ Source } & \multicolumn{2}{|c|}{$\begin{array}{l}\text { Average number of } \\
\text { cells in clumps }\end{array}$} & \multicolumn{2}{|c|}{$\begin{array}{l}\text { Percentage of the aggrega- } \\
\text { tes in the population }\end{array}$} & \multicolumn{2}{|c|}{ MGR (underlined higher MGR); } \\
\hline & & parental & $\begin{array}{l}\text { trans } \\
\text { formed }\end{array}$ & parental & $\begin{array}{l}\text { trans } \\
\text { formed }\end{array}$ & $\begin{array}{l}\text { Parental/t-test } \\
\text { results *stat.signif- } \\
\text { icant }\end{array}$ & transformed \\
\hline $\begin{array}{l}\text { *UWOPS83-787 } \\
\text { mating type a, }\end{array}$ & $\begin{array}{l}\text { Fruit. Opuntia } \\
\text { stricta }\end{array}$ & 6.2 & 1.0 & $29.9 \pm 6.6$ & $2.3 \pm 1.3$ & $\begin{array}{l}\frac{0.51}{\mathrm{t}^{*}{ }_{10 ; 0}} \pm 0.0004 \\
=6.86\end{array}$ & $0.39 \pm 0.02$ \\
\hline $\begin{array}{l}\text { *UWOPS87-2421 } \\
\text { mating type a }\end{array}$ & $\begin{array}{l}\text { Fruit. Opuntia } \\
\text { megacantha }\end{array}$ & 10.3 & 1.7 & $62.2 \pm 4.2$ & $9.7 \pm 2.5$ & $\begin{array}{l}\underline{0.53} \pm 0.04 / \\
\mathrm{t}_{10 ; 0.014}^{*}=2.97\end{array}$ & $0.48 \pm 0.02$ \\
\hline $\begin{array}{l}{ }^{*} \text { DBVPG } 1373 \\
\text { mating type a }\end{array}$ & Soil & 6.4 & 1.7 & $73.6 \pm 3.5$ & $24.7 \pm 1.6$ & $\begin{array}{l}0.42 \pm 0.02 / \\
\mathrm{t}^{*}{ }_{10 ; 0.000003}=-9.39\end{array}$ & $\underline{0.51} \pm 0.02$ \\
\hline $\begin{array}{l}\text { UWOPS87-2421 mating } \\
\text { type alpha }\end{array}$ & $\begin{array}{l}\text { Fruit. Opuntia } \\
\text { megacantha }\end{array}$ & 6.1 & 1.9 & $89.4 \pm 0.8$ & $8.9 \pm 2.5$ & $\begin{array}{l}0.50 \pm 0.01 / \\
\mathrm{t}_{10 ; 0.024}^{*}=-2.67\end{array}$ & $\underline{0.53} \pm 0.03$ \\
\hline $\begin{array}{l}\text { *Y55 } \\
\text { mating type a }\end{array}$ & Grapes & 9.9 & 1.7 & $73.3 . \pm 11.3$ & $22.5 \pm 2.2$ & $\begin{array}{l}0.56 \pm 0.01 / \\
\mathrm{t}^{*}{ }_{10 ; 0.000003}=9.26\end{array}$ & $\underline{0.57} \pm 0.01$ \\
\hline $\begin{array}{l}\text { DBVPG } 1106.3 \\
\text { mating type a }\end{array}$ & Grapes & 7.5 & 1.6 & $64.4 \pm 1.4$ & $18.3 \pm 1.2$ & $\begin{array}{l}\underline{0.56} \pm 0.01 / \\
\mathrm{t}_{10 ; 0.2}=-1.39\end{array}$ & $0.52 \pm 0.01$ \\
\hline $\begin{array}{l}378604 X \\
\text { mating type alpha }\end{array}$ & $\begin{array}{l}\text { Clinical isolate } \\
\text { (Sputum) }\end{array}$ & 3.4 & 2.0 & $46.0 \pm 5.1$ & $19.1 \pm 3.4$ & $\begin{array}{l}0.51 \pm 0.01 / \\
\mathrm{t}^{*}{ }_{10 ; 0.0005}=-4.99\end{array}$ & $\underline{0.54} \pm 0.01$ \\
\hline $\begin{array}{l}\text { S288c mating type } \\
\text { alpha. reference }\end{array}$ & $\begin{array}{l}\text { Rotting fig; labora- } \\
\text { tory strain }\end{array}$ & 1.7 & 1.7 & $7.3 \pm 2.3$ & $7.3 \pm 2.3$ & $0.49 \pm 0.01$ & $0.49 \pm 0.01$ \\
\hline
\end{tabular}

uid yeast peptone dextrose (YPD) medium and grown at $30^{\circ} \mathrm{C}$ overnight to allow the plasmid to "pop out" by homologous recombination between the two copies of the $A M N 1$ gene sequence. From each culture, $\sim 10^{5}$ cells were plated onto 5-Fluoro-ortic acid medium (5-FOA) plates, which selects for cells lacking a functional URA3 gene, in order to obtain cells which had lost the plasmid and thus retained only one $A M N 1$ gene (containing either the endogenous or the W303 allele). Colonies that grew on 5-FOA medium were chosen for microscopic observation. The number of aggregates, and the average number of cells within the aggregates, were counted using a Bürker chamber (hemocytometer). Approximately eight transformant clones showing no aggregate formation were obtained from each of the starting strains, and were then for subjected to genomic confirmation to determine whether they carried the expected non-clumping W303 AMN1 allele. Genomic DNA from each clone was obtained using Gentra DNA purification Kit with prior lysis of the cell wall by lyticase treatment. To amplify the $A M N 1$ gene region, the following primers (designed by J. Koschwanez) were used: F:ACGAACT'TCCCAGGAGACGACACA; R: AAAGGCCTCCCGCGGACTTAAAACAGAAC, with the PCR program: $95^{\circ} \mathrm{C}$ $-3 \mathrm{~min} ; 34$ cycles of $\left[95^{\circ} \mathrm{C}-30 \mathrm{~s} ; 55^{\circ} \mathrm{C}-30 \mathrm{~s} ; 72^{\circ} \mathrm{C}\right.$ $-1 \mathrm{~min}] ; 72^{\circ} \mathrm{C}-10 \mathrm{~min}$. The PCR products were treated with the Exo-Sap clean-up kit (Fermentas) and then Sanger sequenced with the Big Dye Terminator kit 3.1 (ABI), using the F primer, and run on a $3130 \times 1$ genetic analyzer (ABI). The sequences were analyzed using BioEdit software. Clones verified to have the GTT (Val) at codon 368 of the AMN1 gene, i.e., the W303 allele, were analyzed using the 5 assays described below. (i) Clumpiness. The ancestral and transformed strains were grown in liquid YPD medium at $28^{\circ} \mathrm{C}$. Then the populations were diluted, and single cells and aggregates were counted using a microscope (Nikon Eclipse E400) and Bürker chamber. Each of the populations was also photographed using a microscope (Nicon Eclipse 80i) and Lucia software (Quality Capture 2560×1920, ex. time 1/125s) (phase contrast PlanApo 40×/0.95) (Table 1). A minimum of 3 independent colonies of each transformant and 6 independent colonies of the control (untransformed parent) were checked. The average percentage of single and double cells and aggregates (defined as groups of cells containing more than 2 cells) was calculated (Table 1). To calculate the average number of cells in the clumps, the number of cells in at least 250 aggregates was counted using the microscope. (ii) Population density. Populations of parental and transformed strains were grown for 2 days in liquid YPD media. The density was assessed by counting cells from serially diluted populations using hemocytometer. (iii) Monocolony phenotype. Using a micromanipulator, four single cells in stationary phase from each parental (non-transformed) strain and from one of its transformed derivatives were placed on growth and stress media (YPD, synthetic dextrose minimal medium with uracil, SD+ura, $\mathrm{ZnSO}_{4}, \mathrm{NaCl}$ ). Cells were allowed to form colonies at $28^{\circ} \mathrm{C}$ for 3 weeks, then scanned (Epson Perfection 2480 Photo), washed from the plate. Washed plates were scanned then to check for the invasive colony growth. (iv) Population viability. Four of the parental and transformed strains in triplicate (marked with an asterisk in Table 1) were incubated at $28^{\circ} \mathrm{C}$ in $10 \mathrm{ml}$ of water for 14 weeks. Every two weeks, a sample of each liquid culture was diluted and plated on YPD, and the viable cells that formed colonies were then counted. (v) Maximum growth rate. Microtiter plates with microcultures of $200 \mu \mathrm{l}$ YPD media were incubated with agitation of $1.250 \mathrm{rpm}$ (Tetramax 1000; Heidolph Instruments) and subjected to a wide-band optical density (OD) measurement every 20-60 minutes using the Infinite m200 Microplate Reader (Tecan). Before each OD measurement, parental strain populations were mixed using a pipette, which does not break small aggregates. The OD read-outs were log-transformed, and used to determine the range of exponential growth. The latter was done by finding lower and upper limits of OD between which the correlation coefficient (Pearson's) $r$ was the highest when averaged over all cultures within 


\section{microscope YPD image}
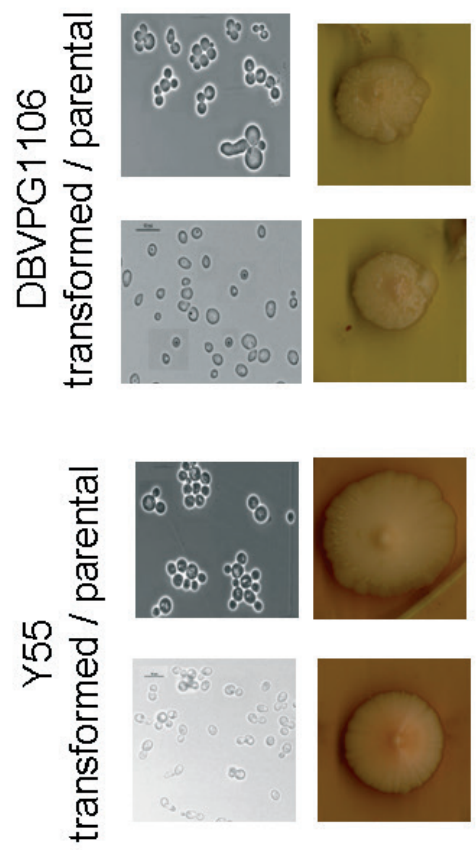

YPG
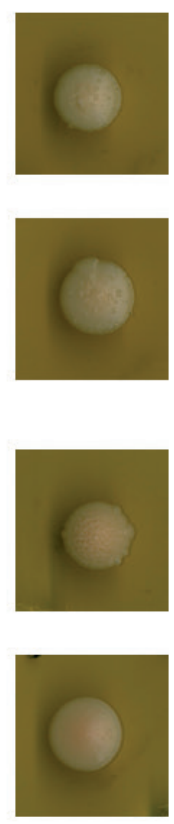

\section{SD+ura}
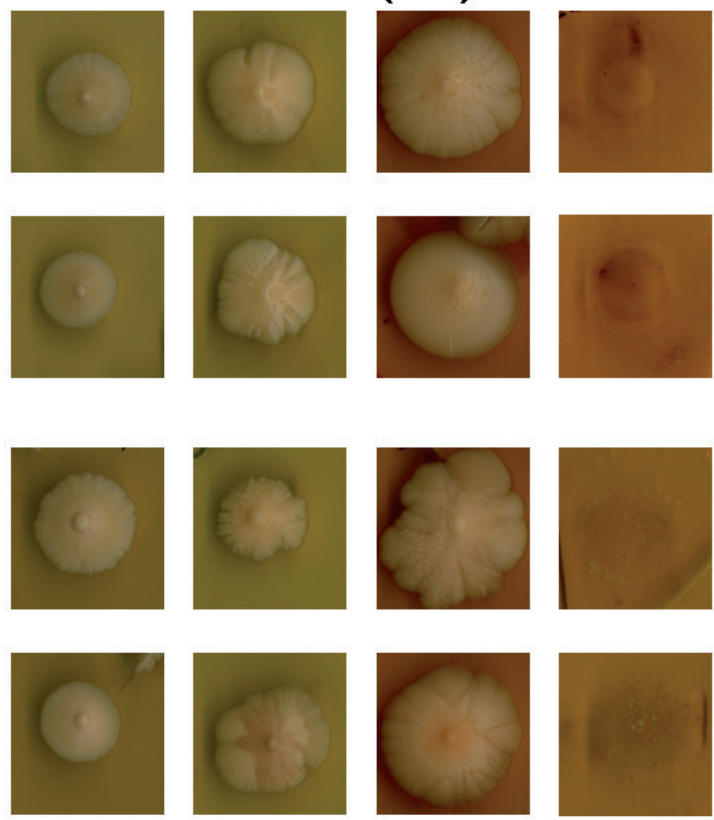

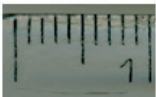

Figure.1. Scans of monocolonies of two strains that were chosen: DBVPG1106 and Y55. Small bars on the microscope images represent $10 \mu \mathrm{m}$.

one test environment. This usually yielded no less than 5 time points with the mean squared $r$ at 0.999 and rarely dropping below 0.99 . The final estimator of fitness was the coefficient of slope in a linear regression. Every strain was assayed independently 6 times.

\section{RESULTS AND DISCUSSION}

We obtained at least one clone from each strain ( $\mathrm{Ta}$ ble 1) that was positively verified by double sequencing to have the GTT (Val) at codon 368 of the AMN1 gene, i.e., the W303 allele. Below are results from the five assays that those strains were subjected to:

(i) Clumpiness. We observed substantial reduction in the size and percentage of the aggregates in all of the transformed strains (Table 1). In the transformed strains, the highest number of cells counted in a clump was 5, while some aggregates in the non-transformed strain were composed of more than 24 cells. These results were similar irrespective of the media tested (YPD, $\mathrm{SD}+$ ura, $\mathrm{ZnSO}_{4}, 0.5 \mathrm{mg} / \mathrm{ml}, \mathrm{NaCl}, 4 \%$ ), liquid and agar plates (stable environments) and temperature $\left(22^{\circ} \mathrm{C}, 38^{\circ} \mathrm{C}\right.$ and $35^{\circ} \mathrm{C}$ ) (data not shown). At the same time, an increase in the number of single and double cells in a population of transformed strains was observed.

(ii) Population density. The transformation had no effect on the maximum average population density (ANOVA $\mathrm{F}_{1,46}=3.55 ; \mathrm{p}=0.07001$ ) which was measured using hemocytometer.

(iii) Monocolony phenotype. Most strains demonstrated no noticeable differences in the colony morphology. However, in minimal media (SD+ura) and under oxidative stress $\left(\mathrm{ZnSO}_{4} ; 0.5 \mathrm{mg} / \mathrm{ml}\right)$, parental colonies were more wrinkled and striated compared to the smoother surface of the transformed colonies (Fig. 1).
The "washing test" for invasive growth (Piccirillo \& Honigberg, 2010) showed no difference in the phenotype for all strains tested on all the media (Fig. 1).

(iv) Population viability. The ratio of $\log \mathrm{N}$ paren$\mathrm{tal} /$ transformed remained stable, suggesting that transformation did not influence viability (Regression $\mathrm{r}=$ $0.03 ; \mathrm{F}_{1,91}=0.63 ; \mathrm{p}=0.81$ ).

(v) Maximum growth rate. There was a significant difference between all but one parental and transformed strains (Table 1), with the largest difference of $1.2 \%$ (strain UWOPS83-787). The effect of transformation on growth rate varied for different strains.

In summary, we describe a method to eliminate or drastically diminish the clumpy aggregating phenotype in a yeast strain by changing a single codon in the $A M N 1$ gene. Several comparisons of the ancestral and $A M N 1$ W303 transformed strains show that this change has a minor influence on growth rate and colony morphology (in certain media). In our opinion these differences are not drastic. Such modification allows for using a growing number of strains isolated from various ecological origins and of different phylogeny distances for comparative studies, isolation of fraction of cells in a similar physiological state and research on origin of multicellularity. However, there is need for other assays to fully characterise the effect of codon replacement we propose here. We hope that this method and the modified strains could be useful for scientists interested in research using wild isolates of yeast Saccharomyces cerevisiae.

\section{Aknowledgements}

We thank Katarzyna Pawlik and Jakub Pajak for technical assistance, John Koschwanez for sharing the plasmid, method of transformation and manuscript edition, Gianni Liti and Francisco Cubillos for the collec- 
tion of strains and Barbara Dunn for edition and comments. The work was funded by the National Science Centre (NCN) HARMONIA grant for DW-S, DEC2011/01/M/NZ8/01031.

\section{REFERENCES}

Botstein D, Fink GR (2011) Yeast: an experimental organism for 21st century biology. Genetics 189: 695-704.

Bruckner S, Mosch HU (2012) Choosing the right lifestyle: adhesion and development in Saccharomyces cerevisiae. Fems Microbiol Rev 36: 25-58.

Cubillos FA, Louis EJ, Liti G (2009) Generation of a large set of genetically tractable haploid and diploid Saccharomyces strains. Fems Yeast Res 9: 1217-1225.

Diezmann S, Dietrich FS (2009) Saccharomyces cerevisiae: population divergence and resistance to oxidative stress in clinical, domesticated and wild isolates. PLoS One 4: e5317.

Gietz RD, Woods RA (2002) Transformation of yeast by lithium acetate/single-stranded carrier DNA/polyethylene glycol method. Guide to Yeast Genetics and Molecular and Cell Biology, Pt B. 350: 87-96.

Goffeau A, Barrell BG, Bussey H, Davis RW, Dujon B, Feldmann H, Galibert F, Hoheisel JD, Jacq C, Johnston M, Louis EJ, Mewes HW, Murakami Y, Philippsen P, Tettelin H, Oliver SG (1996) Life with 6000 genes. Science 274: 546-567.
Koschwanez JH, Foster KR, Murray AW (2011) Sucrose utilization in budding yeast as a model for the origin of undifferentiated multicellularity. PLoS Biol. 9: e1001122.

Liti G, Carter DM, Moses AM, Warringer J, Parts L, James SA, Davey RP, Roberts IN, Burt A, Koufopanou V, Tsai IJ, Bergman CM, Bensasson D, O'Kelly MJ, van Oudenaarden A, Barton DB, Bailes E, Nguyen AN, Jones M, Quail MA, Goodhead I, Sims S, Smith F, Blomberg A, Durbin R, Louis EJ (2009) Population genomics of domestic and wild yeasts. Nature. 458: 337-341.

Mewes HW, Albermann K, Bahr M, Frishman D, Gleissner A, Hani J, Heumann K, Kleine K, Maierl A, Oliver SG, Pfeiffer F, Zollner A (1997) Overview of the yeast genome. Nature 387: 7-8.

Mortimer RK, Johnston JR (1986) Genealogy of principal strains of the yeast genetic stock center. Genetics 113: 35-43.

Piccirillo S, Honigberg SM (2010) Sporulation patterning and invasive growth in wild and domesticated yeast colonies. Res Microbiol 161: 390-398.

Schacherer J, Shapiro JA, Ruderfer DM, Kruglyak L (2009) Comprehensive polymorphism survey elucidates population structure of Saccharomyces cerevisiae. Nature 458: 342-345.

Yvert G, Brem RB, Whittle J, Akey JM, Foss E, Smith EN, Mackelprang R, Kruglyak L (2003) Trans-acting regulatory variation in Saccharomyces cerevisiae and the role of transcription factors. Nat Genet 35: 57-64. 